\title{
ARTICLE
}

\section{Imagination Cannot Justify Empirical Belief}

\author{
Jonathan Egeland* \\ Filosofiska institutionen, SE 106 92, Stockholm \\ ${ }^{*}$ Corresponding author. Email: Jonathan.egeland.harouny@philosophy.su.se
}

(Received 21 December 2018; revised 17 May 2019; accepted 18 June 2019;

first published online 28 August 2019)

\begin{abstract}
A standard view in the epistemology of imagination is that imaginings can either provide justification for modal beliefs about what is possible (and perhaps counterfactual conditionals too), or no justification at all. However, in a couple of recent articles, Kind (2016; Forthcoming) argues that imaginings can justify empirical belief about what the world actually is like. In this article, I respond to her argument, showing that imagination doesn't provide the right sort of information to justify empirical belief. Nevertheless, it can help us take advantage of justification that we already have, thereby enabling us to form new doxastically justified beliefs. More specifically, according to the view I advocate, imagination can contribute to one's satisfaction of the proper basing condition - which turns propositional justification into doxastic justification - but without conferring any new justification that the subject isn't already in possession of upon their beliefs. Very little attention has been devoted to the distinction between propositional and doxastic justification in the literature on imagination, and the view I here argue for takes up a yet-to-be occupied position.
\end{abstract}

Keywords: Imagination; justification; propositional and doxastic justification; simulation

\section{Introduction}

We sometimes find ourselves engaged in imagination. For example, one can imagine that the streets of Rome currently are busy, that Wittgenstein often felt lonely during his stay in his Norwegian hut, or that non-human animals suddenly one day acquire the ability to converse with us humans. Indeed, one can imagine many things, some of which are true and others which are contrary to fact. With this virtually all philosophers agree. However, they do disagree about the philosophical, and in particular epistemic, significance of imagination.

In the last couple of decades, philosophers have increasingly started to look at imagination as a phenomenon of epistemological interest. One important question they've asked is: can imaginings teach us anything about the world? A standard answer has become that imaginings can either provide justification for modal beliefs about what is possible (and perhaps counterfactual conditionals too), ${ }^{1}$ or no justification

\footnotetext{
${ }^{1}$ Williamson (2016: 115) says that "one might regard imagination [at least metaphorically] as a form of attention to possibilities.” Cf. Yablo (1993), Menzies (1998), and Chalmers (2002).

(C) The Author(s) 2019. This is an Open Access article, distributed under the terms of the Creative Commons Attribution licence (http://creativecommons.org/licenses/by/4.0/), which permits unrestricted re-use, distribution, and reproduction in any medium, provided the original work is properly cited.
} 
(except for trivial beliefs about the internal world) ${ }^{2}$ at all. ${ }^{3}$ One reason it is standardly believed that imaginings cannot teach us about how the world actually is is that imaginings are governed by the subject's own volition and therefore don't exhibit the necessary sort of sensitivity to what the world is like. This has recently been called the Up-To-Us Challenge by Magdalena Jackson (2018), and the idea, as Peter Langland-Hassan (2016: 62 ) has put it, is that imagination cannot improve your epistemic positon any more than "handing yourself a dollar" can improve your finances. Consider, for example, the following passage from Colin McGinn:

Imagining is subject to the will, while believing is not ... Belief is a commitment to truth, and the truth cannot be willed into being. But imagining is not a commitment to truth, even possible truth, so there is no obstacle to willing it; imagining is simply contemplating it, holding it before the mind ... That there is strong evidence against a proposition is no bar to imagining that it is true, since I am not, qua imaginer, in the business of conducting an investigation of how the world is ... When I am in the business of investigating the world, I adopt an attitude of evidential sensitivity, and my beliefs are formed accordingly; but not so when I am merely imagining. Here I am indifferent to how things actually are. (McGinn 2004: 132)

In this article, I will take a closer look at recent attempts by Amy Kind (2016; Forthcoming) to argue against the standard view. As she sees it, imagination can justify empirical belief, and, in certain cases, the justification it provides is strong enough to turn the justified belief into knowledge. In response, I will argue that Kind fails to properly acknowledge the difference between propositional justification and doxastic justification, ${ }^{5}$ and, moreover, that when one does, it becomes clear that imagination cannot justify empirical belief. More specifically, according to the view I advocate, imagination can contribute to one's satisfaction of the proper basing condition - which turns propositional justification into doxastic justification - but without conferring any new justification that the subject isn't already in possession of upon their beliefs. Very little attention has been devoted to the distinction between propositional and doxastic justification in the literature on imagination, and the view I here argue for takes up a yet-to-be occupied position.

\section{Kind on the epistemic role of imagination}

According to Kind (2016; Forthcoming), just because imagination is under the imaginer's volitional control, it doesn't follow that it cannot teach us anything about the world. More specifically, she tells us that as long as the "imaginative project" satisfies (or at least comes close to satisfying) a couple of important conditions, it can justify empirical belief in propositions about how the world actually is. Paraphrasing a bit, the conditions are as follows:

\footnotetext{
${ }^{2}$ By "the internal world" I mean one's mental states.

${ }^{3}$ For a useful discussion about imaginings, the conceivability-possibility link, and justification, see Gendler and Hawthorne (2002: Introduction).

${ }^{4}$ Cf. Wittgenstein (1981: \$632): “Imaginings tell us nothing about the external world ... Imaginings are subject to the will ... It is just because forming an imagining is a voluntary activity that it does not instruct us about the external world."

${ }^{5}$ Here I use the now standard terminology first introduced by Firth (1978). Propositional justification is about the justification someone has for believing/withholding/disbelieving certain propositions, whereas doxastic justification is about the justified beliefs (or other doxastic attitudes) someone holds.
} 
The Reality Constraint: the world must be imagined as it really is in all relevant respects.

The Change Constraint: if one's imaginative project requires one to imagine a change to how one believes the world to be, then it must be constrained by all and only the relevant consequences of that change. (Kind 2016: 150-51) ${ }^{6,7}$

Having thus informed us about conditions under which imagination can justify belief about how the world is, in order to support her view, Kind draws our attention to the animal scientist and inventor Temple Grandin. Grandin reportedly has an amazing ability to visually imagine how things work. Moreover, as Kind tells us, in her design process she uses her imagination much in the same way designers nowadays use threedimensional computer simulations, and supposedly with no less efficiency. One of the inventions Grandin developed in this way was a new dip vat design with the purpose of making it easier to rid cows of parasites. Before Grandin's invention, cows entering the dip vat would often panic, making things difficult for both the animals and the farmers. However, according to Kind,

By taking a 'cow's eye view' of the situation, Grandin diagnosed the problems with the existing structures and was able to create an alternative in which the cows would calmly enter and exit the equipment voluntarily, without any use of force. Her design process, however, took place entirely in her mind. (Kind Forthcoming: 9)

Moreover, Grandin confidently believed in the efficiency of her new design, even before she saw it in action. Kind lists three propositions it is plausible to think that Grandin believed after imagining the new dip vat design:

\section{Dip vats built to these specifications are more effective than currently existing dip vats.}

An entry built to these specifications makes things easier on the cows than the entry on currently exiting dip vats.

Cows entering a dip vat built to these specifications don't panic. (Kind Forthcoming: 10)

\footnotetext{
${ }^{6}$ Cf. Gendler's (2003) condition of imaginative mirroring.

${ }^{7}$ Williamson seems to think that when we are engaged in imagination, we usually satisfy these (and other similar) conditions: "The default for the imagination in its primary function may be to proceed as 'realistically' as it can, subject to whatever derivations the thinker imposes by brute force ... Thus the imagination can in principle exploit all our background knowledge in evaluating counterfactuals" (Williamson 2007: 143).

Similarly, a few pages later he says: "The best developed simulation theories concern our ability to simulate the mental processes of other agents (or ourselves in other circumstances), putting ourselves in their shoes, as if thinking and deciding on the basis of their beliefs and desires ... Such cognitive processes ... would involve just the sort of constrained use of the imagination indicated above. How would Mary react if you asked to borrow her car? You could imagine her immediately shooting you, or making you her heir; you could even imagine reacting like that from her point of view, by imagining having sufficiently bizarre beliefs and desires. But you do not. Doing so would not help you determine how she really would react. Presumably, what you do is to hold fixed her actual beliefs and desires (as you take them to be just before the request); you can then imagine the request from her point of view, and think through the scenario from there. Just as with the falling rock, the imaginative exercise is richly informed and disciplined by your sense of what she is like" (Williamson 2007: 148). Cf. Williamson (2016).
} 
And, Kind tells us, it seems plausible that Grandin's beliefs were justified. Also, if we consider someone running a computer simulation of Grandin's new dip vat design, showing cows peacefully entering and being immersed in the pesticide, watching the simulation does appear to provide justification for belief in the three propositions above. And since computer simulations are sufficiently similar to what Kind calls "imaginative simulations" - especially Grandin's - the same is true of them too. (See Kind Forthcoming: 11-12.)

\section{Reply: Imagination and the distinction between propositional and doxastic justification}

Now, the problem with this argument is not that Grandin doesn't have justification for her beliefs. Rather, it is that it isn't her imagination that is responsible. A more plausible explanation of the scenario above is that Grandin's imagination contributes to the formation of her beliefs, but not to their justification. It is, I suggest, her background beliefs and perceptual experiences that really are responsible for justifying them.

However, Kind anticipates this objection and says that Grandin's background beliefs and perceptual experiences aren't sufficient for justifying her beliefs about the new dip vat design because she also needs an "understanding" of how cows will react to the new design. And, she says, it is her imagination that provides this understanding. In order to illustrate her point, Kind asks us to consider an owner of a cattle-handling facility with lots of knowledge about cows and dip vats. Indeed, the owner has "all the beliefs that are embedded in the programming of [a] computer simulation" that is able to demonstrate how cows are likely to react to any particular dip vat. Before the owner has run and observed the simulation, he lacks the necessary understanding for having justified beliefs about the efficiency of Grandin's new design. It is only after the simulation is run and he acquires a "cow's view" of the situation that his beliefs about the design are justified. And, moreover, since the computer simulation is sufficiently similar to Grandin's "imaginative simulation," it is only after she is done imagining her design in action that her beliefs become justified. (See Kind Forthcoming: 13.)

Here I agree that there is a difference in the justificatory status of Grandin's beliefs before and after the "imaginative simulation" and that the difference is due to the understanding it provides her with. However, I think the difference most plausibly should be understood as a difference in doxastic justification, not propositional justification. Let me elaborate.

Grandin's "imaginative simulation" is constrained by her background beliefs and perceptual experiences of cows and dip vats. It is an attempt to try to figure out what is going to happen when the cows go through the dip vat given the information that she already has about cows and dip vats. Likewise, the cattle facility owner's computer simulation tries to figure out what is going to happen when the cows go through the dip vat given the information that he has about cows and dip vats (recall that we're told his beliefs exhaust the programming of the simulation). Now, the simulations in these cases don't provide any new information about the world that isn't already somehow contained in Grandin's or the cattle facility owner's beliefs and experiences; they only try to figure out what their consequences actually are. ${ }^{8,9}$ As a result, they don't

\footnotetext{
${ }^{8}$ Cf. Sartre (1972: 7): “The image teaches us nothing ... No matter how long I look at an image, I shall never find anything in it but what I put there."

${ }^{9}$ Kind (Forthcoming: 17) tells us that "a computer programmer can be provided with new information by the outputs of her program, even though the program contains nothing but what she put in it." Normally, this is of course the case. However, since the owner of the cattle-handling facility in the example
} 
confer any justification upon their beliefs about the efficiency of the new dip vat design. However, the simulations do provide them with an understanding that enables them to take advantage of the epistemic resources (i.e., the propositional justification) provided by their background beliefs and perceptual experiences. More specifically, they give a clear picture of what the consequences of their beliefs and experiences are, and, as a result, Grandin and the owner of the cattle facility are able to take advantage of the justification they already have by forming (doxastically justified) beliefs about the efficiency of the new design on their proper justificatory basis. ${ }^{10}$ Grandin's imagination therefore helps her to convert propositional justification into doxastic justification, thereby improving the justificatory status of her beliefs, but without conferring any justification upon them. ${ }^{11}$

But wait a minute. Am I not contradicting myself when I say that Grandin's imagination helps produce doxastic justification and that it doesn't confer justification? Or am I perhaps saying that doxastic justification isn't bona fide justification? If you feel like these questions threaten my view, then you might have missed my point. First, doxastic justification - which, according to the traditional analysis, is propositional justification plus proper basing - is genuine justification; justifiably held belief is a real epistemic achievement. Second, claiming that a mental process (like imagination) that helps produce doxastic justification doesn't confer justification isn't contradictory. To see why that is so, consider Grandin's beliefs again. Prior to her imaginative simulation they are, I agreed, propositionally justified. In other words, she has justification to hold those beliefs, but without holding them in a justified manner. After her imaginative simulation, however, she is able to hold them in a justified manner. By using her imagination, she is able to properly base her beliefs on that which gives her propositional justification to hold them (which is what I mean when I say that it helps her take advantage of the epistemic resources she already has), but without conferring any new justification that she didn't already have upon them. My point is simply that imagination can contribute to the satisfaction of the proper basing condition, but not the propositional justification condition - both of which justifiably held belief requires. ${ }^{12}$

above has "all the beliefs that are embedded in the programming of the computer simulation," this is not the case for him. And since Kind's claim is that Grandin's "imaginative simulation" is analogous to that of the owner of the cattle facility, and not the regular computer programmer, the fact that the regular computer programmer can learn something new about the world from the outputs of her program doesn't tell us anything about why the same should be true of Grandin and her imaginings.

${ }^{10}$ Most likely, there will be some connection between the duration and detail of the imaginative episode, on the one hand, and, on the other hand, the extent to which it enables the subject to take advantage of the justification he or she already has by basing their beliefs on their proper justificatory basis. Indeed, I suspect that imagining an object or situation for a longer period time and from a variety of different perspectives in response to different probes is more likely to put the imaginer in a good position to take advantage of the epistemic resources in their possession than if they simply imagine the object/situation for a short amount of time or from very few perspectives. Moreover, this also explains why a skilled imaginer, like Grandin, usually will be able to acquire more doxastically justified beliefs from her imaginings than a less skilled imaginer. Thanks to an anonymous referee for suggesting that I make this clear.

${ }^{11}$ Kind (Forthcoming: 18 ) also talks about examples having to do with which shoes to wear, whether one's children are ready to watch a scary movie, which kinds of office one prefers, and whether a colleague's ill-advised emails were sent with nasty intentions. The response offered above also applies to these cases. Imagining the relevant scenarios doesn't confer any justification, but rather enables you to take advantage of the justification you already have.

${ }^{12} \mathrm{An}$ interesting question is whether imagination is unique in this regard. Are imaginings the only mental states/processes that enable one to take advantage of the justification one already has, but without conferring any new justification upon one's beliefs? Although I suspect the class of such mental processes to be 
So, to reiterate my argument, because the kind of realistic imaginings Kind focuses on simply don't provide any new information about the world, they cannot confer any justification upon empirical belief. ${ }^{13}$ However, another problem Kind identifies as she responds to her imaginary interlocutor is that a denial that imagination can confer justification amounts to a denial that perception can confer justification. And, by modus tollens, since everyone should agree that perception can confer justification, they should also agree that imagination can too. This is how she puts her point:

Suppose that Grandin did not engage in her imaginative simulation and that she didn't herself develop the specifications for a dip vat with this new design - instead, it was designed and built by one of her rivals. Normally, we would think her seeing her rival in action would contribute to the justification of her belief in its efficacy. But on the line currently being pursued by the proponent of [the view that imagination cannot confer justification], that can't be right. Given that she has the prior beliefs that she does, her seeing the design in action is epistemically irrelevant to the justification of her belief in its efficacy. And this seems absurd. The fact that someone has a vast store of prior knowledge about cows does not mean that they couldn't learn something from seeing the device in action. And likewise, the fact that one has all this prior knowledge does not mean that one couldn't learn anything from imagining the device in action. (Kind Forthcoming: 14)

The problem with this piece of reasoning, however, is that it begs the question against my response by assuming that imaginings are epistemically analogous to perceptual experiences insofar as they either both can or can't confer justification. But this assumption is entirely unmotivated. Perception can of course justify empirical belief; this much is not controversial. But whether the same holds true of imagination is controversial and cannot simply be established by saying that it does. Indeed, perception and imagination appear to be disanalogous in important ways that motivate the opposite view. Whereas perception does provide us with new information about what the world is like - visually, there seems to be a garden over here; auditorily, there seems to be dog over there imagination doesn't. Indeed, one cannot simply imagine one's way to new information about the world that isn't already somehow contained in one's prior beliefs and perceptual experiences. Kind's response to the objection that imagination can contribute to the formation of empirical belief, but not to their justification, therefore fails.

\section{Conclusion}

For the reasons given above, I therefore think that Kind's argument that imaginings can justify empirical belief isn't sound. It fails to take into account the difference between

rather small, I do believe that there are other such processes with a similar epistemic function. Consider, for example, dreams. While dreams don't provide us with any new information about the world, and hence don't confer any (propositional) justification upon our doxastic attitudes, they do, at least in certain circumstances, appear to be able to bring old information to light in a way that enables the dreamer to form new doxastically justified beliefs. Indeed, the dreamer might for example be presented with information about his childhood in such a way that he realizes that he used to be badly behaved as a child. Thanks to an anonymous referee for bringing this issue to my attention.

${ }^{13}$ Although it seems to me unclear exactly how the argument of Williamson (2016) should be understood, there is at least one reading of it under which it is making the same point as Kind's argument. Now, if that indeed is the correct reading, then my response to Kind applies equally well to Williamson. If, however, that isn't the correct reading, then Williamson appears to be making a similar point to the one I make - namely, that imagination can help us improve our epistemic position by taking advantage of epistemic resources that we already are in possession of. 
propositional justification and doxastic justification. However, when one does, it becomes clear that imagination can contribute to doxastic justification by enabling one to form one's beliefs on their proper justificatory basis, even though it doesn't confer any new justification that one didn't already have upon them - or so I've argued. Moreover, there are epistemically significant differences between imagination and (e.g.) perception - viz., the kind of information they provide - that motivate and explain why the standard view about the epistemic role of imagination is true. Whereas perception can provide new information about the world, imagination cannot. ${ }^{14}$

\section{References}

Chalmers D.J. (2002). 'Does Conceivability Entail Possibility?' In T.S. Gender and J. Hawthorne (eds), Conceivability and Possibility, pp. 145-200. Oxford: Oxford University Press.

Firth R. (1978). 'Are Epistemic Concepts Reducible to Ethical Concepts?' In A. Goldman and J. Kim (eds), Values and Morals, pp. 215-29. Dordrecht: Kluwer.

Gendler T.S. (2003). 'On the Relation between Pretense and Belief.' In M. Kieran and D.M. Lopes (eds), Imagination, Philosophy and the Arts, pp. 125-41. New York, NY: Routledge.

Gendler T.S. and Hawthorne J. (eds) (2002). 'Introduction.' In Conceivability and Possibility, pp. 1-70. Oxford: Oxford University Press.

Jackson M.B. (2018). 'Justification by Imagination.' In F. Macpherson and F. Dorsch (eds), Perceptual Imagination and Perceptual Memory, pp. 209-26. Oxford: Oxford University Press.

Kind A. (2016). 'Imagining Under Constraints.' In A. Kind and P. Kung (eds), Knowledge Through Imagination, pp. 145-59. Oxford: Oxford University Press.

Kind A. (Forthcoming). 'How Imagination Gives Rise to Knowledge.' In F. Macpherson and F. Dorsch (eds), Perceptual Memory and Perceptual Imagination. Oxford: Oxford University Press.

Langland-Hassan P. (2016). 'On Choosing What to Imagine.' In A. Kind and P. Kung (eds), Knowledge Through Imagination, pp. 61-84. Oxford: Oxford University Press.

McGinn C. (2004). Mindsight: Image, Dream, Meaning. Cambridge, MA: Harvard University Press.

Menzies P. (1998). 'Possibility and Conceivability: A Response-Dependent Account of Their Connections.' In R. Casati (ed.), European Review of Philosophy, Volume 3: Response-Dependence, pp. 255-77. Stanford, CA: CLI Publications.

Sartre J-P. (1972). The Psychology of the Imagination. London: Methuen.

Williamson T. (2007). The Philosophy of Philosophy. Oxford: Wiley-Blackwell.

Williamson T. (2016). 'Knowledge by Imagining.' In A. Kind and P. Kung (eds), Knowledge Through Imagination, pp. 113-23. Oxford: Oxford University Press.

Wittgenstein L. (1981). Zettel, trans. G. E. M. Anscombe. Oxford: Basil Blackwell.

Yablo S. (1993). 'Is Conceivability a Guide to Possibility?' Philosophy and Phenomenological Research 53, $1-42$.

Jonathan Egeland is a PhD candidate in philosophy at Stockholm University. His research interests are primarily focused on epistemology, philosophy of science, 19th century German philosophy, and certain issues in the philosophy of mind. He currently works for the Diaphora project - a European research and training network for collaborative research on the nature of philosophical problems, their resilience, the sources of persistent divergence of expert opinion about them, and their relation to conflicts in the practical sphere.

\footnotetext{
${ }^{14}$ Work on this paper has received funding from the European Union's Horizon 2020 Research and Innovation Programme under Grant Agreement no. 675415. For helpful comments and discussions, thanks to Mikael Janvid and Åsa Wikforss.
}

Cite this article: Egeland J (2021). Imagination Cannot Justify Empirical Belief. Episteme 18, 507-513. https://doi.org/10.1017/epi.2019.22 